\title{
RHEOLOGICAL PROPERTIES OF LATVIAN ILLITE CLAYS
}

\author{
Inga DUSENKOVA *, Valentina STEPANOVA, Jana VECSTAUDZA, \\ Vitalijs LAKEVICS, Juris MALERS and Liga BERZINA-CIMDINA
}

\author{
Institute of General Chemical Engineering, Riga Technical University, Azenes 14/24, Riga, LV-1048, Latvia., \\ phone +37167089275 , fax +37167089109 \\ *Corresponding author's e-mail: inga.dusenkova@rtu.lv
}

(Received November 2012, accepted May 2013)

\begin{abstract}
The influence of mineralogical composition, electrical conductivity and $\mathrm{pH}$ on the rheological properties of Latvian illite clays has been investigated. Samples from two deposits have been studied. The average plasticity index of samples from both Laza deposits is 23-25, but from Apriki - around 20. Based on these results, 2 samples with different plasticity indices from each borehole were chosen for further research. All suspensions exhibit yield-pseudoplastic behavior. Samples with the highest amount of clay minerals have the highest plasticity index and apparent viscosity. From 3 samples with similar amount of clay minerals and plasticity index one sample has higher $\mathrm{pH}$ and electrical conductivity and therefore exhibits lower viscosity.
\end{abstract}

KEYWORDS: illite, clay minerals, plasticity, apparent viscosity, mineralogical composition, electrical conductivity

\section{INTRODUCTION}

Clay suspensions have complex rheological properties. Viscosity and plasticity of suspensions containing clay minerals are important parameters in materials science, chemical engineering and geology (Bergaya et al., 2006). Clays and clay minerals are used as additives in drilling fluids, ceramics, paints (Zhang et al., 2003) and as excipients in cosmetic and pharmaceutical preparations (Carretero et al., 2010).

The rheological properties of mineral suspensions depend on the size, shape, surface charge and concentration of the particles and on the type of mineral (Czibulya et al., 2010; Gridi-Bennadji et al., 2011; Ndlovu et al., 2011; Yalcin et al., 2002). Clay minerals have plate-like particles with permanent negative charge on their surface and $\mathrm{pH}$ dependent charge on the edge. Clay mineral particles in suspensions can form three modes of particle association: face-to-face (FF), edge-to-face (EF) and edge-to-edge (EE). FF leads to the formation of lamellar aggregates, EE forms band-like aggregates and EF forms 3 dimensional "house of cards" structures (Gridi-Bennadji et al., 2012; Ndlovu et al., 2011; Zhang et al., 2003). These aggregation modes are highly influenced by $\mathrm{pH}$ value, amount of clay particles in suspension and presence of different electrolytes. At low $\mathrm{pH}$ values positively charged edges and negatively charged basal faces of clay particles form the "house of cards" structure, which leads to increase of viscosity. However, at high $\mathrm{pH}$ values, when both basal and edge faces are negatively charged, the inter-particle attractions become weaker, and therefore viscosity is reduced (Bergaya et al., 2006; Loginov et al., 2008). Viscosity can be changed also by processing techniques such as shear and blending (Iannicelli and Millman, 1966) and repeated freeze-thaw cycles (Schwinka and Mortel, 1999).

At low concentrations clay minerals in aqueous suspensions exhibit Newtonian properties, where viscous flow occurs in response to stress and the rate of flow is proportional to the applied stress. At high clay concentration the flow can display nonNewtonian properties. Most clay suspensions in water show thixotropic properties (Pantet and Monnet, 2007; Reeves et al., 2006), where clay-water systems are able to restore their structure after mechanical agitation (Mewis and Wagner, 2009).

The most abundant clay mineral in Latvia is illite, however most clays also contain a small amount of kaolinite. There are many studies on the rheological behavior of suspensions of one clay mineral, mostly smectite (Gridi-Bennadji et al., 2011; Hajjaji et al., 2010; Morris and Zbik, 2009; Paumer et al., 2008), bentonite (Abu-Jdayil, 2011; Christidis et al., 2006; Kelessidis et al., 2007) and kaolinite (Pantet and Monnet, 2007; Ten Teh et al., 2009), but only few on clays containing illite and kaolinite (Modesto and Bernardin, 2008; Schwinka and Mortel, 1999). Clay deposits in Latvia occur in most regions, but only a part of them are being actively mined, mostly to manufacture ceramics and building materials. Clays in Latvia are heterogeneous -mineralogical composition, physical and chemical properties differ between deposits and depths. Clay deposits investigated in this study are not actively mined and have the most common mineralogical composition for Latvian clay deposits. The aim of this study is to evaluate changes and factors that influence viscosity and plasticity of illite clays. 


\section{EXPERIMENTAL}

\subsection{MATERIALS}

Clay samples were obtained from two quaternary deposits in western Latvia - Laza and Apriki. The samples were collected from three boreholes - two in Laza and one in Apriki. The boreholes were approximately $5 \mathrm{~m}$ deep. The distance between boreholes in Laza deposit was $2 \mathrm{~km}$, but between Apriki and Laza deposits - approximately $6 \mathrm{~km}$. Samples were collected after every $50-80 \mathrm{~cm}$, depending on the color, consistence and visible inclusions like limestone, limonite and silt. Plasticity was determined for all collected samples. Samples chosen for further investigation (apparent viscosity, mineralogical composition, electrical conductivity and $\mathrm{pH})$ were air-dried, then matured in distilled water for 1 month and fractionated by wet sieving through 230 mesh $(63 \mu \mathrm{m})$ sieve.

\subsection{METHODS}

\section{Rheological measurements}

The plasticity index was obtained for crude, nonfractionated clay samples from all three boreholes. The Attergberg limits were determined according to GOST 5180-84. The liquid limit was measured using the fall cone test.

For apparent viscosity measurements 6 samples were selected based on previously obtained plasticity indices - one with the highest and one with lower value from each borehole (Table 1). Particle size fraction $<63 \mu \mathrm{m}$ was used. Apparent viscosity was measured for $25,30,35$ and $40 \mathrm{wt} \%$ suspensions. Initial suspensions (50 wt $\%$ of clay samples) were prepared by mixing dry clay samples with distilled water and then maturing for two weeks. The necessary concentrations of clay suspensions were obtained by diluting the initial suspension with distilled water. Prior to measurements, the suspensions were homogenized using mechanical stirrer for 30 minutes with $360 \mathrm{rpm}$, followed by a 5 minute rest time. The measurements were taken with rotational viscometer (Fungilab, Expert series) at room temperature $20 \pm 1^{\circ} \mathrm{C}$.

\section{Mineralogical composition}

The clay and non-clay minerals were identified by X-ray powder diffraction (PANalytical X'Pert PRO diffractometer, with spinning sample holder and

Table 1 Origin and plasticity index for samples used for viscosity determination.

\begin{tabular}{cccc}
\hline Sample & Deposit & Depth, $m$ & Plasticity index \\
\hline A & Laza (1) & $1.3-1.6$ & $21.0 \pm 0.2$ \\
B & Laza (1) & $3.4-4.1$ & $26.8 \pm 0.4$ \\
C & Laza (2) & $2.0-2.5$ & $23.0 \pm 0.3$ \\
D & Laza (2) & $3.4-3.9$ & $26.5 \pm 1.0$ \\
E & Apriki & $2.9-3.3$ & $15.6 \pm 0.8$ \\
F & Apriki & $4.1-4.5$ & $21.4 \pm 0.5$ \\
\hline
\end{tabular}

$\mathrm{X}^{\prime}$ Celerator detector). $\mathrm{Cu} \mathrm{K} \alpha_{1}$ X-rays generated at $40 \mathrm{~mA}$ and $30 \mathrm{kV}$ were used. For identification of clay minerals four X-ray patterns were recorded - for textured (1), saturated with ethylene glycol for $10 \mathrm{~h}$ in $70{ }^{\circ} \mathrm{C}$ (2), textured and heated at $400{ }^{\circ} \mathrm{C}$ (3) and heated at $550{ }^{\circ} \mathrm{C}$, saturated with ethylene glycol, for $2 \mathrm{~h}(4)$.

\section{pH and electrical conductivity}

$\mathrm{pH}$ and electrical conductivity measurements of 25 - 40 wt $\%$ suspensions of clay samples were conducted with HANNA HI $8424 \mathrm{pH}$ meter and HANNA HI 98303 conductivity meter, respectively.

\section{RESULTS AND DISSCUSION \\ 3.1. ATTERBERG LIMITS}

Both liquid and plastic limits (Fig. 1) for samples in all three boreholes are similar, except for three samples from Apriki deposit with a rapid decrease in both limits. These three samples contain more sand than other samples, probably from an inclusion of sandy soil. The variations of Atterberg limits in all boreholes show that the variation of plastic limit values shows less variation than liquid limit, therefore plasticity index is affected mostly by liquid limit. Average plasticity index for samples from Laza deposit is above 20 (approximately 23-26), indicating medium plasticity (Reeves et al., 2006). Whereas in Apriki deposit the average plasticity index is around 20 (leaving out the 3 sandy samples), therefore being between low and medium plasticity. For further investigations 2 samples with differing plasticity indices were chosen from each borehole (Table 1).

All 6 samples (shown in Table 1) contain the same minerals (Table 2). The dominant clay mineral is illite, but from non-clay minerals - feldspar and quartz. Although the plasticity index was calculated for crude samples, but the mineralogical composition for sample fraction $<63 \mu \mathrm{m}$, there is a correlation between the plasticity index and mineralogical composition. Samples with the highest plasticity index (samples B and D) contain also the highest amount of clay minerals. Sample E contains more non-clay minerals than clay minerals, which explains the low plasticity index. As for samples $\mathrm{A}, \mathrm{C}$ and $\mathrm{F}$, the amount of clay minerals as well as their plasticity indices are similar.

\subsection{RHEOLOGICAL BEHAVIOR OF SUSPENSIONS}

Figure 2 shows a typical effect of solid concentration on the apparent viscosity - an increase of solid concentration leads to an increase of the viscosity of suspension. All suspensions exhibit a rapid increase of apparent viscosity, if solid concentration is raised from 30 to $35 \mathrm{wt} \%$.

To describe the rheological behavior of suspensions, Herschel-Bulkley (H-B) model was used:

$\tau=\tau_{0}+m \gamma^{n}$ 
Table 2 Mineralogical composition ( $w \mathrm{t} \%$ ) with standard deviation 2-4 \%.

\begin{tabular}{ccccccccc}
\hline Sample & Illite & Kaolinite & Chlorite & Quartz & Feldspar & Dolomite & Calcite & Muscovite \\
\hline A & 34 & 13 & 8 & 13 & 16 & 5 & 8 & 5 \\
B & 45 & 10 & 6 & 9 & 11 & 4 & 7 & 8 \\
C & 34 & 10 & 8 & 12 & 16 & 6 & 8 & 6 \\
D & 40 & 12 & 9 & 10 & 13 & 3 & 7 & 6 \\
E & 23 & 5 & 7 & 20 & 26 & 7 & 8 & 4 \\
F & 38 & 10 & 3 & 11 & 17 & 7 & 10 & 4
\end{tabular}

a)

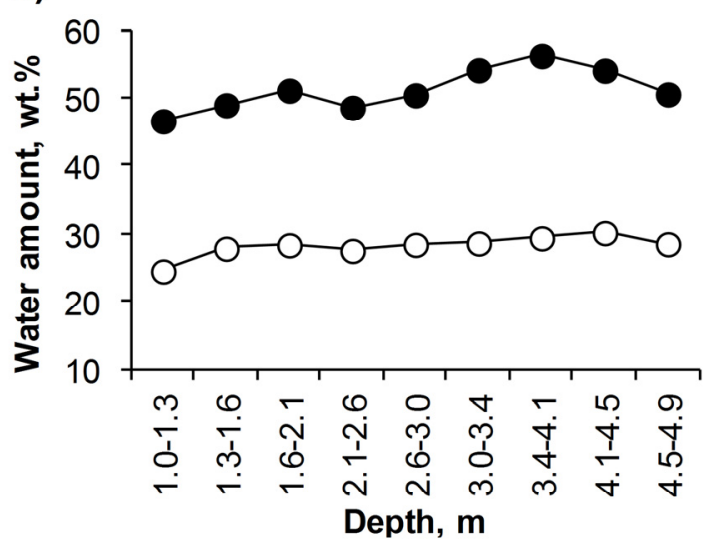

b)

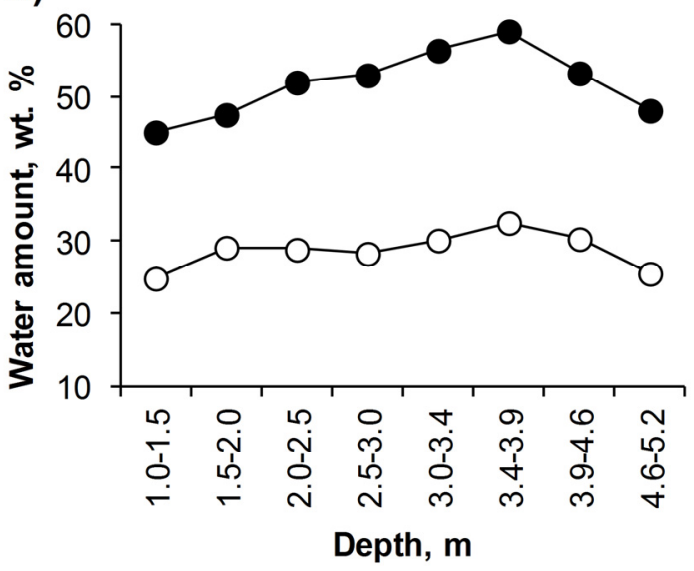

c)

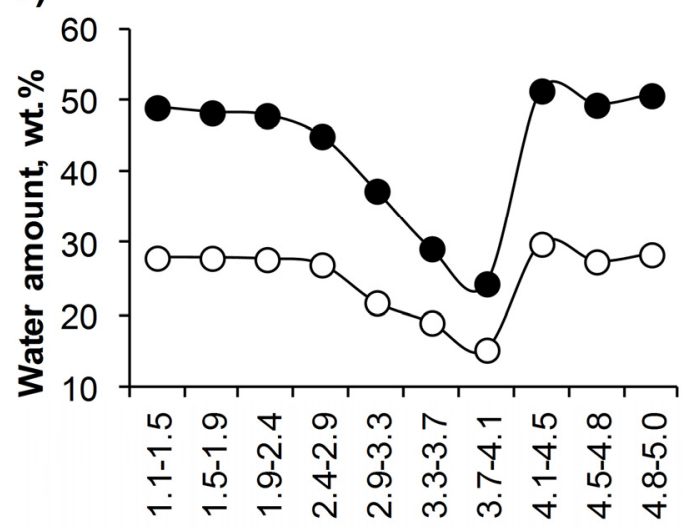

Depth, $\mathbf{m}$

Fig. 1 Distribution of liquid $(\bullet)$ and plastic (o) limits in Laza 1 (a), Laza 2 (b) and Apriki (c) boreholes. where $\tau$ is the shear stress, $\tau_{0}$ is the yield stress, $\gamma$ is the shear rate, $\mathrm{m}$ is the consistency coefficient and $\mathrm{n}$ is the flow behavior index. The H-B model can be used for shear-thinning and shear-thickening fluids (AbuJdayil, 2011; De Blasio, 2011). The H-B model fits well the $\tau$ versus $\gamma$ data, giving correlation coefficients between 0.975 and 0.997 .

The obtained H-B model parameters reported in Table 3 show that basically all suspensions exhibit shear-thinning behavior with yield stress, where $\mathrm{n}<1$ in Eq. (1). The yield stress is absent for samples $F$ and $\mathrm{E}$ at $25 \mathrm{wt} \%$ and $\mathrm{E}$ at $30 \mathrm{wt} \%$. As the solid concentration increases, the flow consistency coefficient also increases, but the flow behavior index decreases. A significant increase of yield stress is observed at clay concentration 30-35 $\mathrm{wt} \%$, denoting the rapid increase in apparent viscosity mentioned before.

Figure 3 shows the flow curves of 25 and 40 $\mathrm{wt} \%$ clay suspensions. As expected, based on the mineralogical composition and plasticity indices, samples B and D have the highest viscosity, but sample E has the lowest. Although samples A, C and $\mathrm{F}$ have similar mineralogical composition and plasticity index, the viscosity of $\mathrm{A}$ and $\mathrm{C}$ is much higher than of $\mathrm{F}$.

\subsection{EFFECT OF PH AND ELECTRICAL CONDUCTIVITY}

The rheological properties of clay suspensions are also influenced by the presence of electrolytes. As the treatment process of clay samples did not include washing, the presence of soluble salts was determined by measurements of electrical conductivity and $\mathrm{pH}$. Electrical conductivity is affected by all soluble salts, while $\mathrm{pH}$ is influenced by alkaline and acidic salts.

The effect of clay concentration on $\mathrm{pH}$ values of suspensions is shown in Figure 4. All suspensions are slightly alkaline. The increase of $\mathrm{pH}$, if more water is added to suspension, is most likely due to dissolution of soluble salts. Sample F has the highest $\mathrm{pH}$ value. Although the differences in $\mathrm{pH}$ values of all suspensions are not high, this can be one of the reasons why sample $\mathrm{F}$ has lower viscosity than samples A and C. As mentioned before, if samples have higher $\mathrm{pH}$ values, suspension becomes less viscous (Bergaya et al., 2006; Loginov et al., 2008).

Electrical conductivity decreases if the suspension is diluted (Figure 5). Clay mineral 

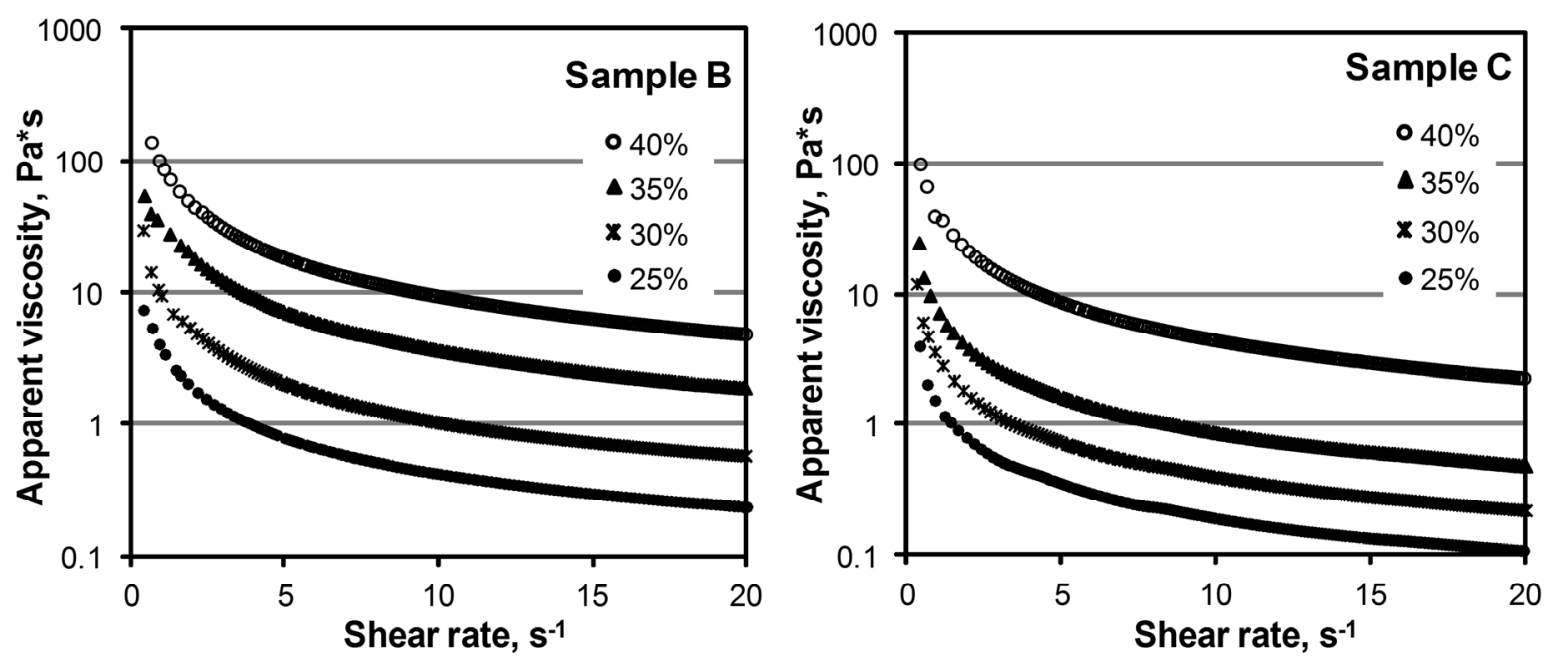

Fig. 2 Apparent viscosity of clay suspensions at different solid concentrations.

Table 3 Herschel-Bulkley model parameters of clay suspensions.

\begin{tabular}{ccccccc}
\hline wt $\%$ & $\mathrm{~A}$ & $\mathrm{~B}$ & $\mathrm{C}$ & $\mathrm{D}$ & $\mathrm{E}$ & $\mathrm{F}$ \\
\hline \multicolumn{7}{c}{ Yield stress $\left(\tau_{0}\right), \mathrm{Pa}$} \\
\hline 25 & 0.9 & 3.1 & 1.2 & 2.5 & 0.0 & 0.0 \\
30 & 2.7 & 9.3 & 2.8 & 7.9 & 0.0 & 0.5 \\
35 & 6.6 & 31.0 & 6.9 & 18.8 & 0.5 & 1.8 \\
40 & 38.3 & 84.9 & 41.3 & 81.9 & 3.1 & 9.3 \\
\hline \multicolumn{7}{c}{ Flow behavior index $(\mathrm{n})$} \\
\hline 25 & 0.53 & 0.45 & 0.58 & 0.50 & 0.31 & 0.62 \\
30 & 0.51 & 0.43 & 0.55 & 0.44 & 0.29 & 0.58 \\
35 & 0.45 & 0.36 & 0.51 & 0.39 & 0.26 & 0.55 \\
40 & 0.43 & 0.33 & 0.47 & 0.37 & 0.24 & 0.49 \\
\hline 25 & 0.16 & 0.41 & 0.22 & 0.23 & 0.09 & 0.09 \\
30 & 0.32 & 0.83 & 0.41 & 0.29 & 0.39 & 0.21 \\
35 & 0.47 & 1.51 & 0.50 & 0.88 & 0.59 & 0.32 \\
40 & 1.21 & 4.22 & 1.00 & 4.98 & 0.62 & 0.49 \\
\hline
\end{tabular}
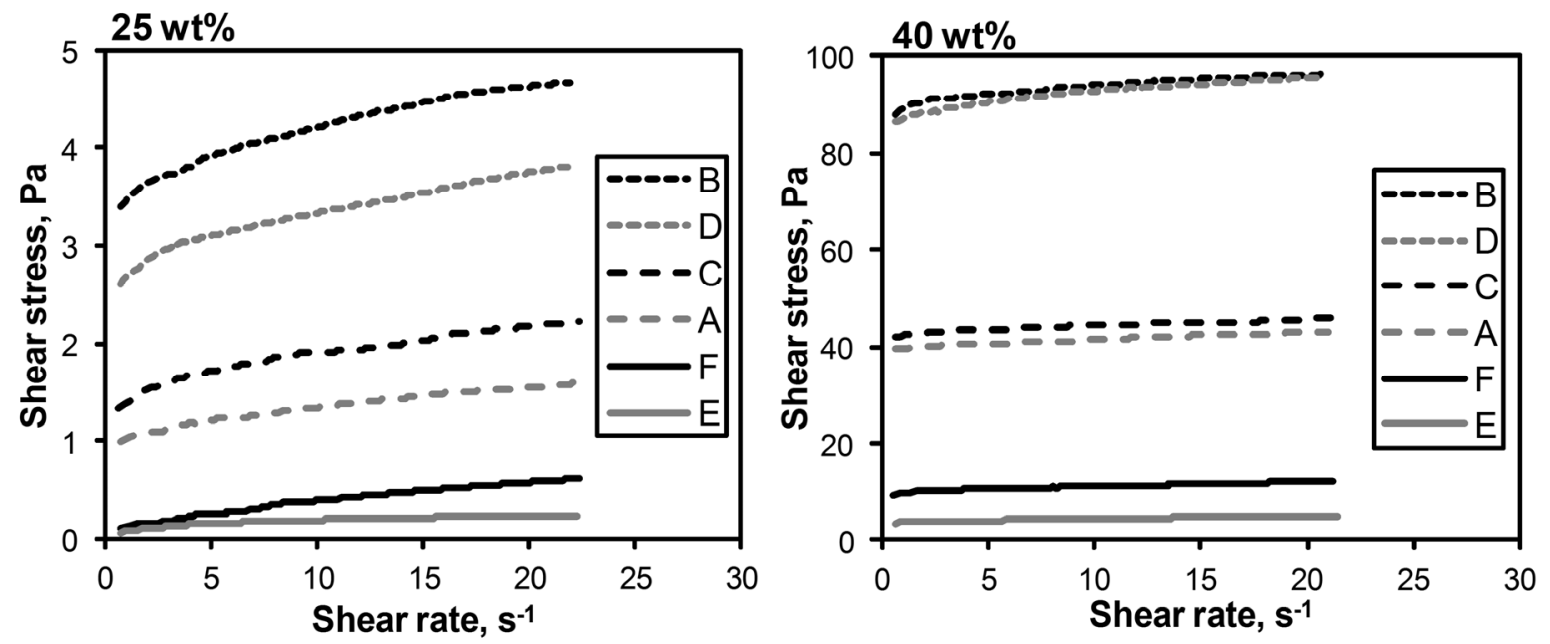

Fig. 3 Rheograms of $25 \mathrm{wt} \%$ and $40 \mathrm{wt} \%$ clay suspensions. 


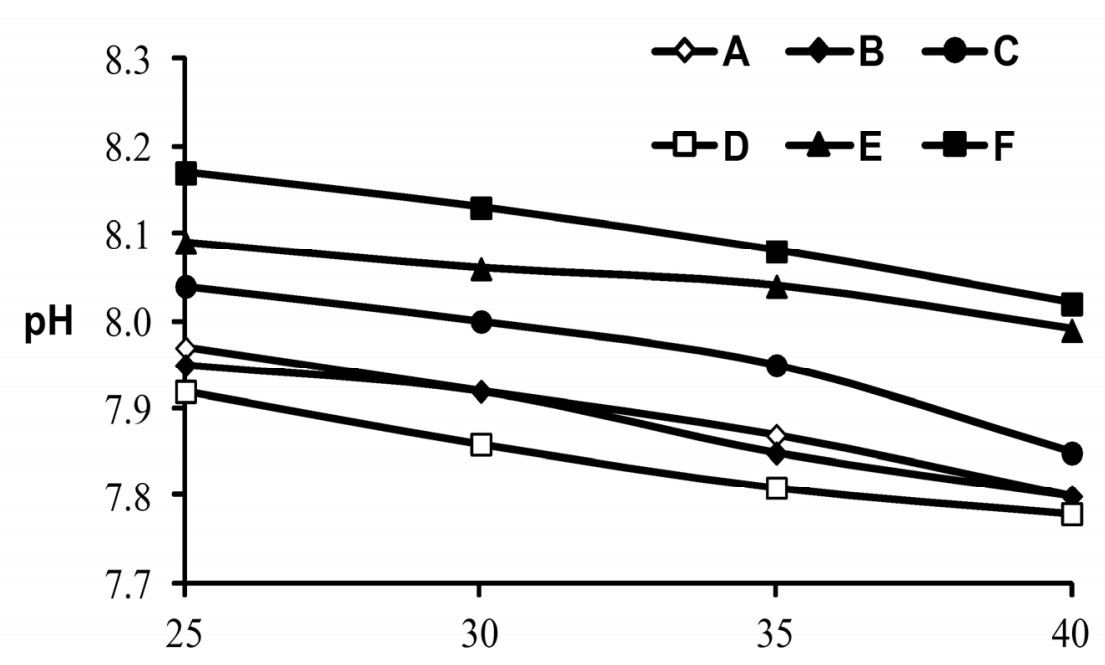

Clay concentration in suspension, wt $\%$

Fig. $4 \mathrm{pH}$ values of clay suspensions.

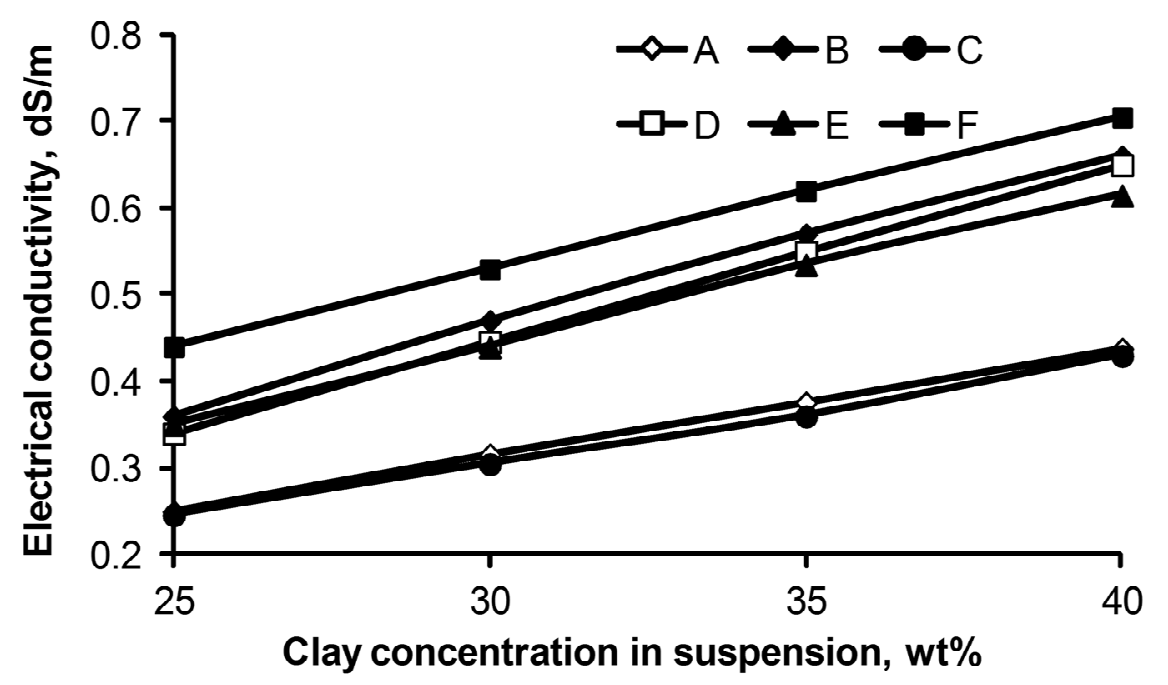

Fig. 5 Electrical conductivity of clay suspensions.

particles have a significant impact on electrical conductivity. When a certain clay/water ratio is reached, conductivity decreases if clay content is decreased (Mojid and Cho, 2006). Sample F has the highest electrical conductivity, which can be another reason for lower apparent viscosity than samples A and C. Since samples B and D have much higher apparent viscosity and contain more clay minerals than sample E, the electrical conductivity of both these samples is mostly influenced by clay mineral particles, but for sample E - by the presence of soluble salts. Abu-Jdayil (2011) and Kelessidis et.al. (2007) concluded that the presence of soluble salts has an influence on the rheological model parameters - if electrolyte concentration is increased, the flow behavior index also increases, but the consistency coefficient decreases. Although the previously mentioned studies have been done with less concentrated bentonite suspensions (1-10 wt \%), there are similar trends seen between samples $\mathrm{A}, \mathrm{C}$ and $\mathrm{F}$ (Table 3).

\section{CONCLUSIONS}

Apparent viscosity and plasticity of Latvian illite clays has been studied. The results show that both apparent viscosity and plasticity can be influenced even by small differences between mineralogical compositions of samples. There is a direct correlation between plasticity index and mineralogical composition. Apparent viscosity is also influenced by presence of soluble salts, because it affects both electrical conductivity and $\mathrm{pH}$ of clay suspensions. The obtained parameters of Herschel-Bulkley rheological model show that $25-40 \mathrm{wt} \%$ suspensions of illite containing clays exhibit shear-thinning behavior.

\section{ACKNOWLEDGEMENTS}

This work has been supported by the European Social Fund within the project «Support for the implementation of doctoral studies at Riga Technical University» and National Research Program of Latvia 2010-2013 "Sustainable use of local resources 
(underground resources, wood, food and transport) new products and technologies (NatRes)" within the project V7804.

\section{REFERENCES}

Abu-Jdayil, B.: 2011, Rheology of sodium and calcium bentinite-water dispersions: Effect of electrolytes and aging time. Int. J. Miner. Process., 98, (3-4), 208-213. DOI: 10.1016/j.minpro.2011.01.001

Bergaya, F., Theng, B.K.G. and Lagaly, G.: 2006, Colloid clay science; Clays in industry. Handbook of clay science. Elsevier Ltd, Amsterdam, 141-245, 499-501.

Christidis, G.E., Blum, A.E. and Eberl, D.D.: 2006, Influence of layer charge and charge distribution of smectites on the flow behaviour and swelling of bentonites, Appl. Clay Sci., 34, (1-4), 125-138. DOI: $10.1016 /$ j.clay.2006.05.008

Czibulya, Z., Tombácz, E., Szegi, T., Michéli, E. and Zsolnay, A.: 2010, Standard state of soil dispersions for rheological measurements. Appl. Clay Sci., 48, (4), 594-601. DOI: 10.1016/j.clay.2010.03.009

Carretero, M. and Pozo, M.: 2010, Clay and non-clay minerals in the pharmaceutical and cosmetic industries Part II. Active ingredients. Appl. Clay Sci., 47, (3-4), 171-181. DOI: 10.1016/j.clay.2009.10.016

De Blasio, F.V.: 2011, Non-Newtonian Fluids, Mudflows, and Debris Flows: A Rheological Approach (Chapter 4). Introduction to the Physics of Landslides, 89-130.

Gridi-Bennadji, F., Lecomte-Nana, G.L., Bonnet, J.P. and Rossignol, S.: 2012, Rheological properties of montmorillonitic clay suspensions: Effect of firing and interlayer cations. J. Europ. Ceram. Soc., 32, (11), 2809-2817. DOI:10.1016/j.jeurceramsoc.2011.11.018

Hajjaji, W., Hachani M, Moussi, B., Jeridi, K., Medhioub, M., López-Galindo, A., Rocha, F.,Labrincha, J.A. and Jamoussi, F.: 2010, Mineralogy and plasticity in clay sediments from north-east Tunisia. J. African Earth Sci., 57, (1-2), 41-46.

DOI: $10.1016 /$ j.jafrearsci.2009.07.007

Iannicelli, J. and Millman, N.: 1966, Relation of viscosity of kaolin-water suspensions to montmorillonite content of certain Georgia clays. Clays Clay Miner., 14, $347-$ 354.

Jen Teh, E., Leonga, Y.K., Liua, Y., Fourieb, A.B. and Faheyb, M.: 2009, Differences in the rheology and surface chemistry of kaolin clay slurries: The source of the variations, Chem. Engin. Sci., 64, (17), 38173825. DOI: 10.1016/j.ces.2009.05.015

Kelessidis, V.C, Tsamantaki, C. and Dalamarinis, P.: 2007, Effect of $\mathrm{pH}$ and electrolyte on the rheology of aqueous Wyoming bentonite dispersions, Appl. Clay Sci., 38, (1-2), 86-96.

DOI: $10.1016 /$ j.clay.2007.01.011
Loginov, M., Larue, O., Lebovka, N. and Vorobiev, E.: 2008, Fluidity of highly concentrated kaolin suspensions: Influence of particle concentration and presence of dispersant. Coll. Surf. A: Physicochem. Engin. Aspects, 325, (1), 64-71. DOI:10.1016/j.colsurfa.2008.04.040

Mewis, J. and Wagner, M.J.: 2009, Thixotropy. Advances in Colloid and Interface Science, 148, 214-227. DOI: $10.1016 /$ j.cis.2008.09.005

Modesto, C.O. and Bernardin, A.M.: 2008, Determination of clay plasticity: Indentation method versus Pfefferkorfn method. Appl. Clay Sci., 40, (1-4), 15-19.

DOI: $10.1016 /$ j.clay.2007.06.007

Mojid, M.A. and Cho, H.: 2006, Estimating the fully developed diffuse double layer thickness from the bulk electrical conductivity in clay. Appl. Clay Sci., 33, (3-4), 278-286. DOI: 10.1016/j.clay.2006.06.002

Morris, G.E. and Żbik, M.S.: 2009, Smectite suspension structural behaviour, Int. J. Min. Proces., 93, (1), 2025. DOI: 10.1016/j.minpro.2009.05.003

Ndlovu, B., Becker, M., Forbes, E., Deglon, D. and Franzidis, J.P.: 2011, The influence of phyllosilicate mineralogy on the rheology of mineral slurries, Min. Engin., 24, (12), 1314-1322. DOI: $10.1016 /$ j.mineng.2011.05.008

Pantet, A. and Monnet, P.: 2007, Liquid-solid transition of kaolinite suspensions. Mech. Mater., 39, (9), 819-833. DOI: 10.1016/j.mechmat.2006.12.004

Paumier, S., Monnet, P. and Pantet, A.: 2008, Rheological behavior of smectite dispersions: The influence of suspension concentration and exchangeable cation. Research Letters in Materials Science, Hindawi Publishing Corporation, $5 \mathrm{pp}$.

Penner, D. and Lagaly, G.: 2001, Influence of anions on the rheological properties of clay mineral dispersions. Appl. Clay Sci., 19, (1-6), 131-142. DOI: $10.1016 / \mathrm{S} 0169-1317(01) 00052-7$

Reeves, M.G., Sims, I. and Cripps, J.C.: 2006, Clay materials used in construction. Geological Society, London, $580 \mathrm{pp}$.

Schwinka, V. and Mortel, H.: 1999, Physico-chemical properties of illite suspensions after cycles of freezing and thawing. Clays Clay Min., 47, (6), 718-725. DOI: 10.1346/CCMN.1999.0470605

Zhang, L.M., Jahns, C., Hsiao, B.S. and Chu, B.: 2003, Synchrotron SAXS/WAXD and rheological studies of clay suspensions in silicone fluid, J. Coll. Interf. Sci., 266, (2), 339-345.

DOI: $10.1016 / \mathrm{S} 0021-9797(03) 00643-\mathrm{X}$ 